\title{
Simulation of a Hybrid Urban Transportation Scooter
}

\author{
Ángeles Cancela ${ }^{1}$, René Lastra ${ }^{1}$, Andrés Alfonsín ${ }^{2}$ and Ángel Sánchez ${ }^{1}$
}

\begin{abstract}
This paper describes a vehicle simulation, originally designed for a hybrid (battery and fuel cell) short urban distances, which can be used to estimate the hybrid vehicle battery, fuel cell and/or hybrid system (both systems working together) range. The simulation model is a function of many mechanical and physical variables that depends not only on the vehicle but also on the ground. It includes the simulation of each of the elements that make up the ecological scooter, so much the driving system whose main element is an electric motor, as the energy storage system whose main element is an acid lead battery fed by a hydrogen fuel cell. An analysis of energy efficiency and operation of the vehicle is made. This Project is framed in a context that seeks an environmentally friendly alternative to current motorcycles in order to reduce polluting emissions, more precisely greenhouse gases, encouraged by the Kyoto Protocol.

From simulation environment, some all these tasks can be performed. The application of this numerical model is to help to conceptual design and unit sizing of a real life-service battery, fuel cellhydrogen and hybrid vehicle, and permits to predict the vehicle range and hydrogen and energy consumption. Results of simulations both driving cycles and real routes test are presented.

Some aspects as $\mathrm{CO}_{2}$ emission saving, hydrogen consumptions an many other have been considered.
\end{abstract}

Keywords: Simulation, Plug-In Hybrid boat, Renewable Energy.

\section{Introduction}

The principal aim of this paper is the development of a numeric model for the integration of a fuel cell in an electric scooter. For this, every single element have beenmodeled separately from the mathematical equations from an electrical consumption point of view and assembled inMatlab-Simulink ${ }^{\circledR}$. A physical approach of the energy system components have been made. Simulations allow us to characterize and understand its operation and draw conclusions from the performance of our electric scooter.The vehicle modeling tries to convert input parameters (performance measures, driving cycle, and types of power and storage components) in the output parameters (vehicle range, distance, power required), Fang (2015). The objective of this project is, in short, to build a computer model for an electric scooter with fuel cell.

\section{Simulation Basis}

To simulate the operation of a fuel cell scooter, a model, based on the physical characteristics of the scooter, was created. This model calculates the instantaneous power required of the engine when traveling through driving patterns and derives various characteristics of numerical operation: power demanded by the vehicle from batteries, fuel consumed during the travel and the amount of energy recovered by regenerative 
brakingWalker (2015).

\section{Wheel power:Traction Effort.}

This is the vehicle propulsion force, transmitted to the ground through the drive wheels. A mass $m$, which advances at a speed $v$ to an inclination angle $\theta$ vehicle is consideredSarrazin (2014). Figure 1 show the principal Simulink simulation block.

The driving force of the vehicle, tractive effort, must meet the following forces:

To overcome the rolling resistance.

To overcome the aerodynamic resistance.

To provide the necessary force to overcome the weight component of the vehicle of the force when it is climbing.

To accelerate the vehicle if the speed is not constant.

\section{Fuel Cell}

In this hybrid vehicle they two PEM fuel cells have been considered Lee (2015). The model corresponds to two batteries with a capacity of $300 \mathrm{~W}$ each. So the overall vehicle power is $1.8 \mathrm{~kW}$, and, for this type of configuration, batteries provide $30 \%$ of the total power of the vehicle needs. Figure 2 show the fuel cell block.

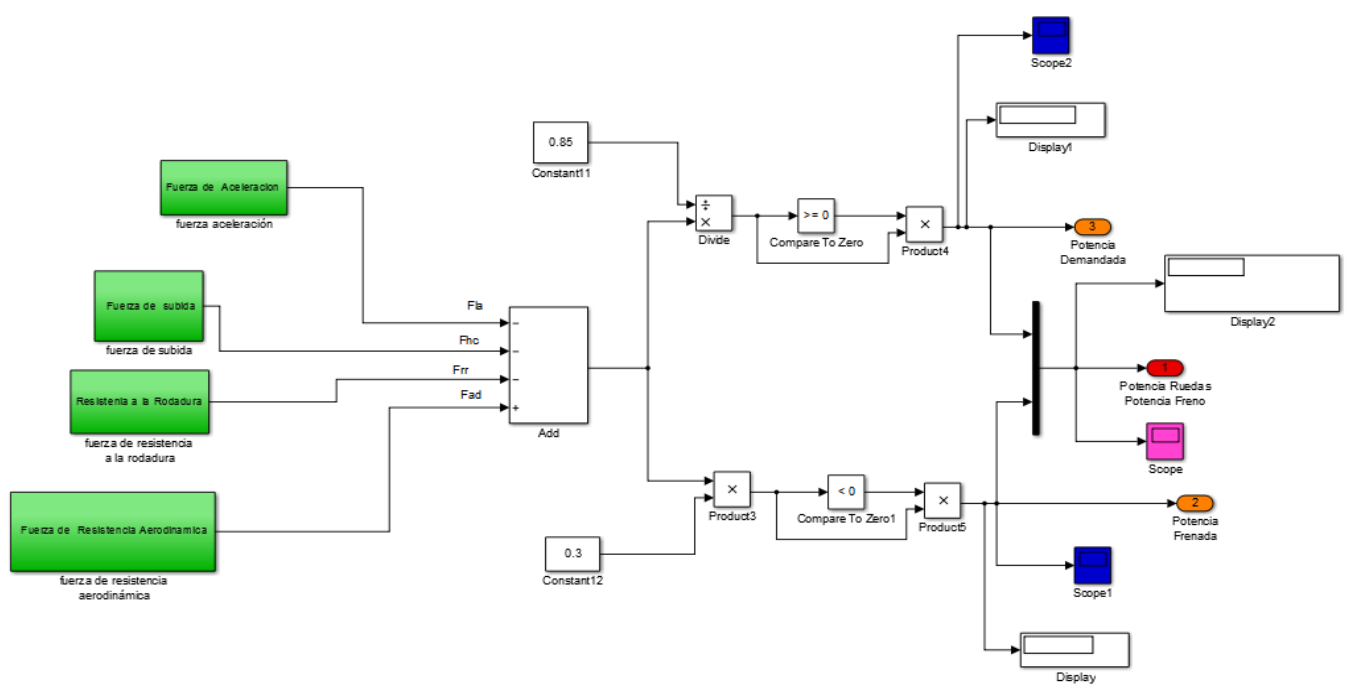

Figura 1: Simulink vebicle power block

\section{Hydrogen Storage}

This simulation piece uses as input the current produced by the fuel cell as a respond to power demand, and as output, the tank hydrogen inner pressure. The simulation block is represented on Figure 3. 


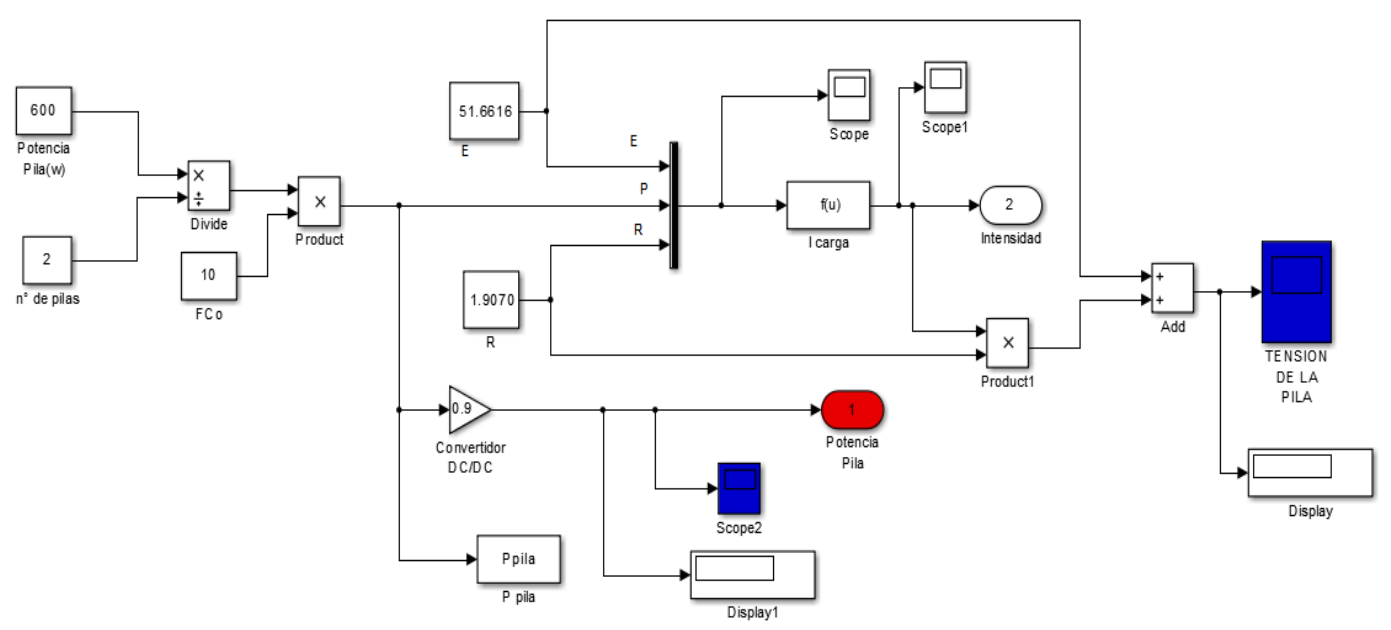

Figure 2:Fuel cell simulation.

\section{Battery Calculations}

Battery is the most complicated model of this simulation. It response to a power demand must be very fast, so it is not necessary to implement an electrochemical model. As occurs with the fuel cell is sufficient to restrict the power and its derivative. However in the case of the battery, consumption calculations has been relatively simple, and, once the necessary flow of hydrogen is found, a simple integral is needed. It is not the same about the battery charge status, whose variation depends not only on the power into or out of them, but other variables such as temperature or intensity. This project involves building a model to accurately predict the behavior of a battery model in different circumstances. This type of model is based more on a thorough analysis of the actual performance data of fundamental physics and chemistry.

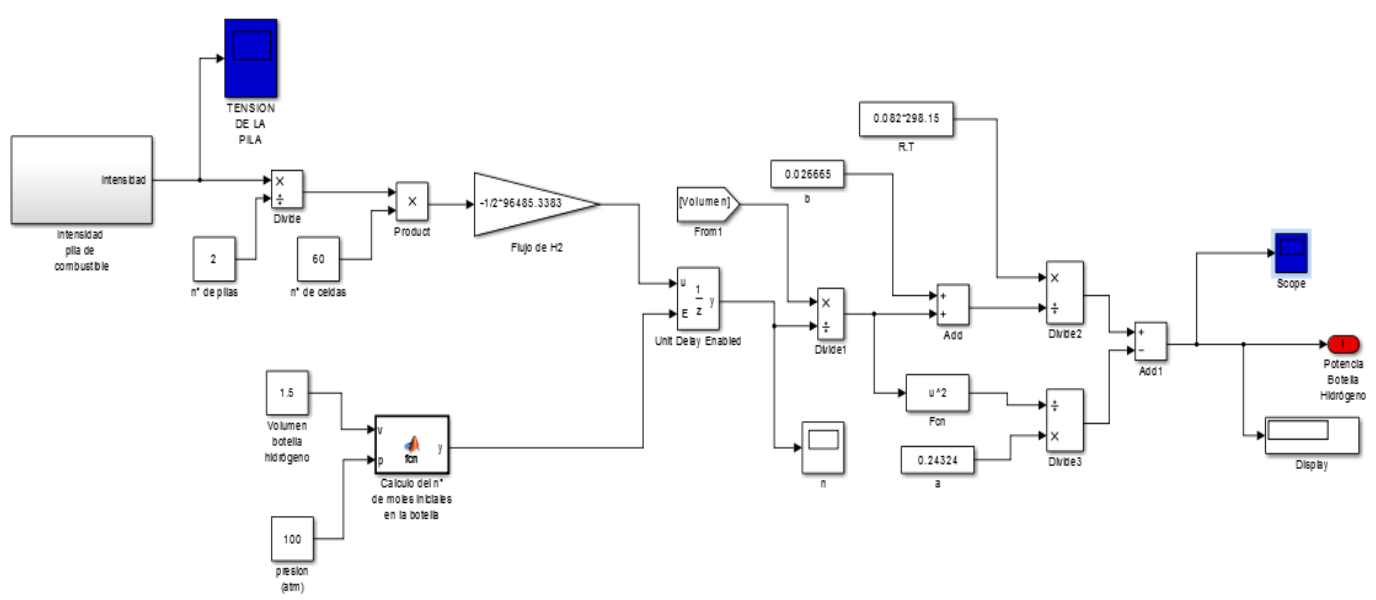

Figura 3. Hydrogen tank block. 
The first thing to establish is the open circuit voltage $\mathrm{E}$, as it changes with the state of charge of the battery.

In the case of sealed lead-acid batteries, the open circuit voltage $E$, is approximately proportional to the state of charge of the battery, showing the voltage of a battery cell. Figure 4 shows the opn circuit voltaje simulation block used to calculate the non-demandvoltage.

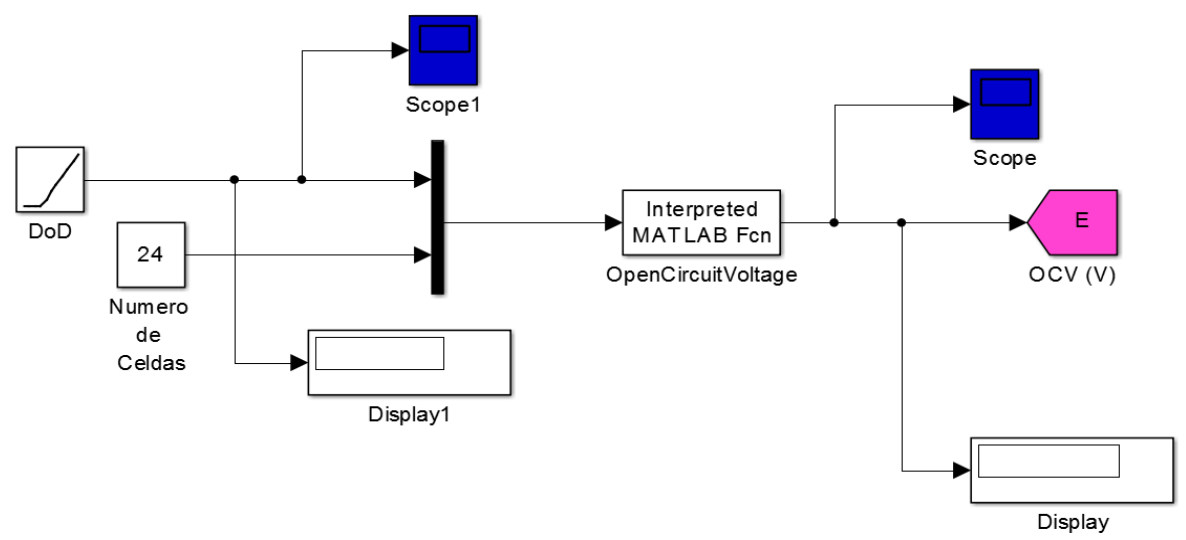

Figura 4. Open Circuit Voltage (OCV) simulation block.

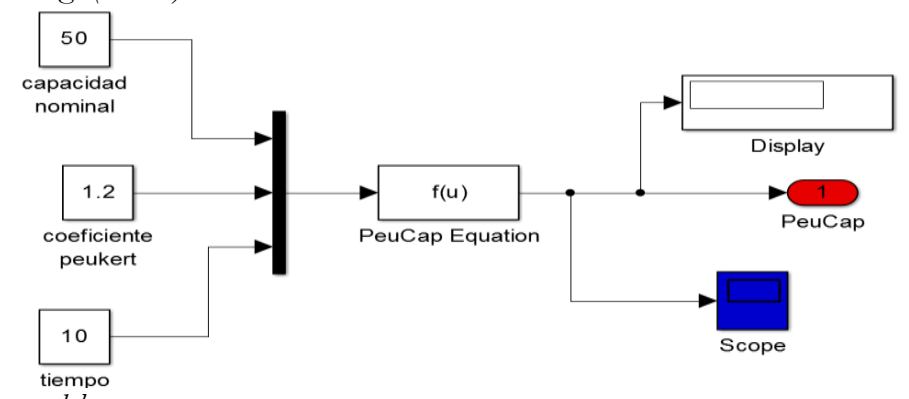

Figura 5. Peukert battery model.

To predict the battery behavior about the scooter current demand responses the Peukert model was used. It is not very accurate at low currents, but for higher currents is of great help and is widely extensible to a different types of batteries by changing the model parameters. Figure 5 represents the Peukert model simulation block.

From previous simulation blocks and those related to battery charge and discharge processes, the State of Charge (SOC) of the battery can be calculated as show in Figure 6. 


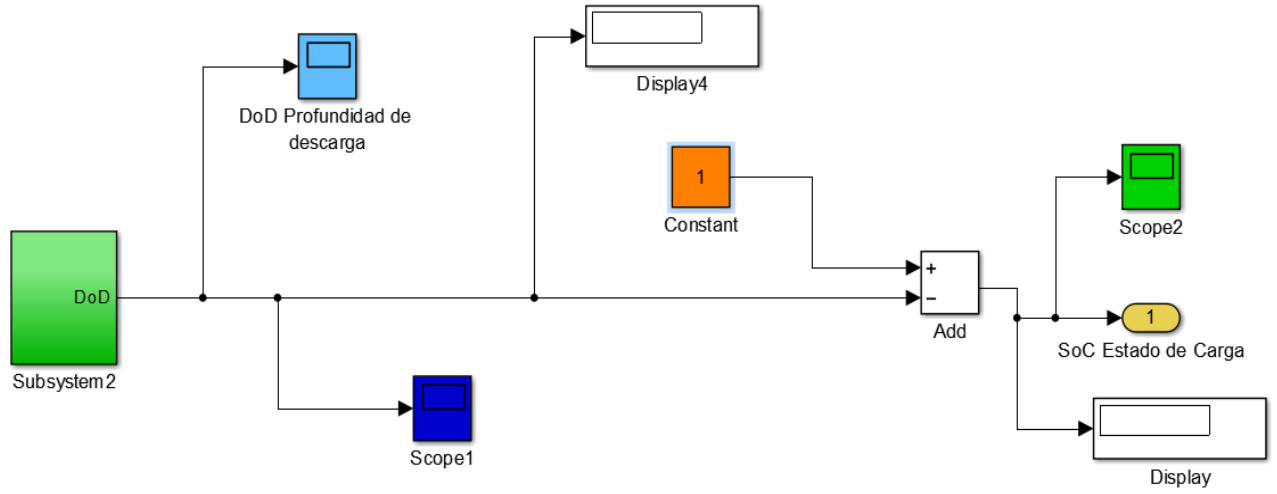

Figure 6.Battery State of Charge (SOC).

\section{Energy Management}

The energy management calculation routine is very important because it drives all the vehicle energy demand. It tries to delivera maximum efficiency to our vehicle. The power to be supplied by the battery is calculated by equation 1, depending on which term provides and which consumes energy. Positive terms meanenergy production and negative terms mean energy consumption Wang (2015).

$$
P_{f c}+P_{b a t}+P_{\text {break }}-P_{\text {wheel }}-P_{\text {aux }}=0
$$

Clearing the value of the battery power, the resulting equation 2 :

$$
P_{\text {bat }}=P_{\text {wheel }}+P_{a u x}-P_{\text {break }}-P_{f c}
$$

The auxiliary power and scooter power are consumptionswhile wheels and braking power are contributions. Because wheels and braking powercannot operate at the same time, we need to make a block previousto the power management block to resolve if one or the other is operating.

$P_{\text {wheel }}$ is the power requirement to operate the vehicle while $P_{\text {break }}$ is the power that provides the vehicle for later a use. This is the same power, but run in reverse. When it is $P_{\text {wheel }}$, the device works as a driver and when $P_{\text {break }}$, the device functions as a current generator which storesthe energy in the battery to be used when needed.

The power of the fuel cell $P_{f c}$ always contributes and is taken in account by the energy management system to be implemented in the control equation. Figure 7 show how energy management system works. 


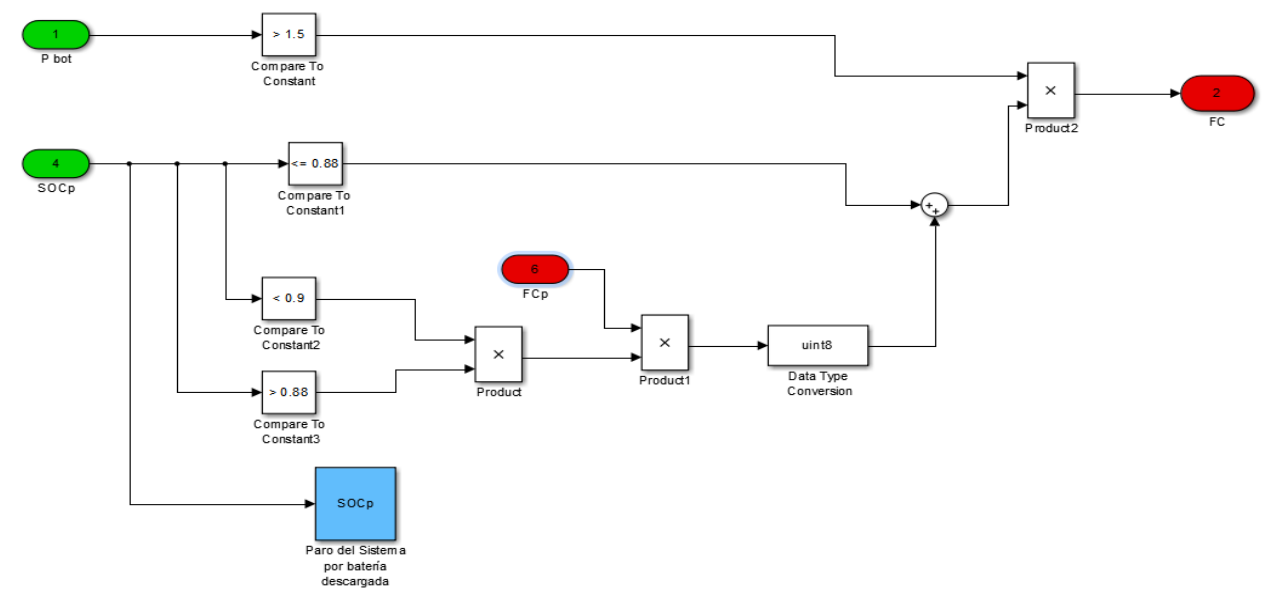

Figure 6.Energy Management System simulation block.

In the calculation of the fuel cell operation it must be taken into account the pressure of the hydrogen tank $\left(P_{\text {tank }}\right)$ which must always be greater than $1.5 \mathrm{~atm}$., When it is smaller the system takes the fuel cell to off. This is to avoid the battery damage due to a lack of hydrogen. We should also keep in mind that the state of charge (SCO) is less than $90 \%$, fuel cell must be turned off. This measure keeps the battery charges over its capacity and overloads, which would cause a deterioration of the battery, do not occurAzidin (2014).

\section{Simulation Results}

From the hybrid hydrogen-battery hybrid scooter several results can be observed, extracting directly from Simulink the variable displays and plots.

- Some variables which can be accessed are:

- Scooter speed.

- Scooter acceleration.

- Acceleration, traction and climbing efforts.

- Rolling and aerodynamic resistances.

- Total demanded power.

- Regenerative braking generated power.

- Open Circuit Voltage.

- Charge and discharge currents.

For example, Figure 7 shows the plot of several (up to battery discharge) ECE15 driving cycles replays for the scooter speed and acceleration. 


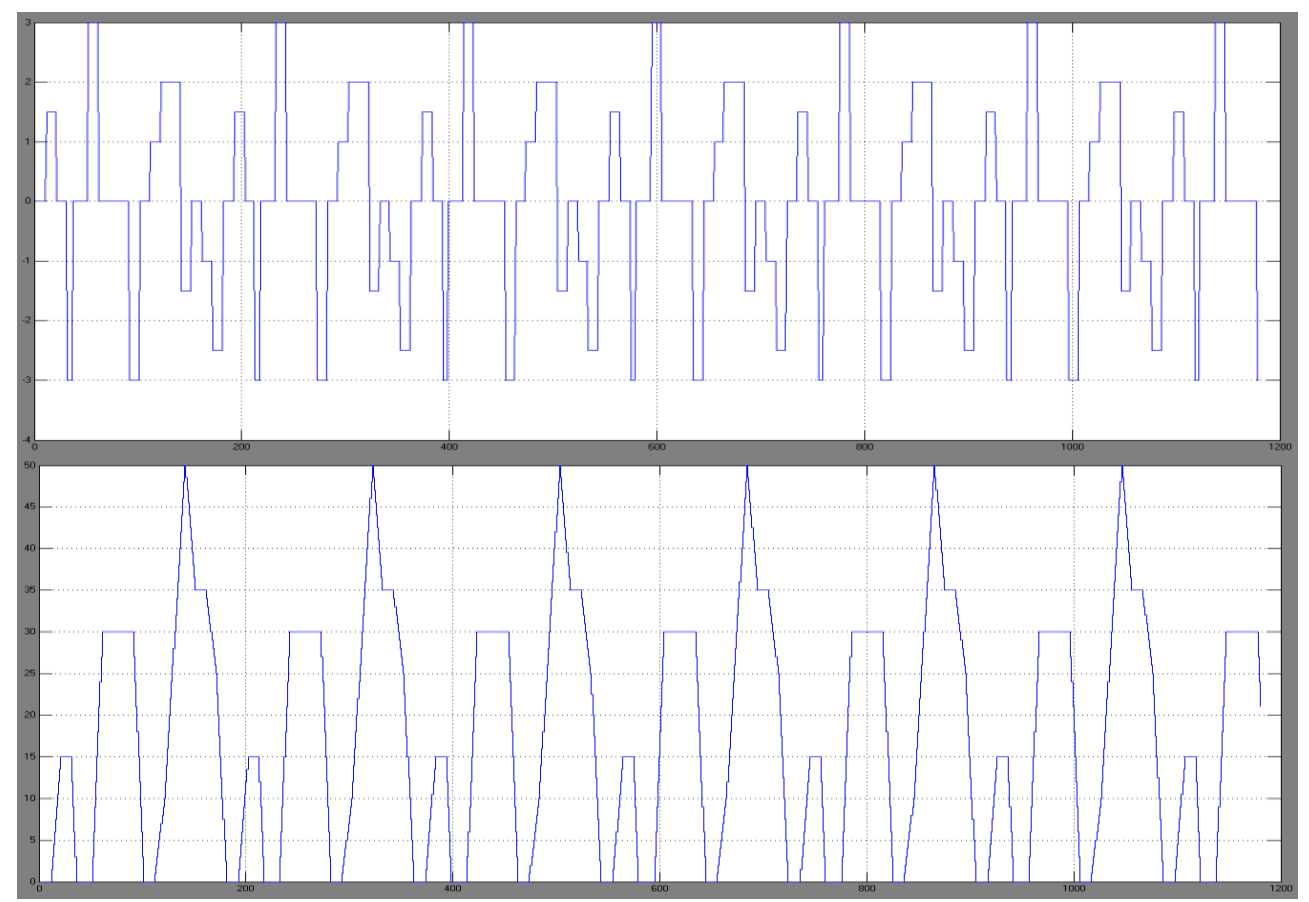

Figure 7. Speend and acceleration vs time plot for a series of ECE15 driving cycle.

\section{Conclusions}

In this project a simulation tool for battery-powered vehicles as well as fuel cell powered by hydrogen, and hybrids of both systems have been presented.

This development includes several parameters that will allow us to configure these simulations for any other similar vehicle.

We have tested this simulation tool, comparing the results with data existing biography from manufacturers.

We also provide the option to particularize our simulations, not only at model level, but including standard cycles, real cycles (routes) that we can get from any GPS.

We have confirmed the good performance of our simulation tools, comparing the results with both the existing biography as manufacturing data.

This simulation tool also allows us to study the influence of few input parameters such as weight, regeneration, battery type, etc., in different routes.

\section{References}

Azidin, F. A., Ghani, Z. A., Hannan, M. A., \&Azah, M. (2014). Intelligent control algorithm for energymanagementsystemoflightelectricvehicles.Journalof Telecommunication, ElectronicandComputerEngineering, 6(2), 37-43. 
Fang, S., Chang, I., \&Yu, T. (2015). Assessmentofthebehaviorandcharacteristicsofelectricscooter use onislands. JournalofCleanerProduction, 108, Part A, 1193-1202.

Lee, C. -., \& Lin, W. -. (2015). Stochasticself-optimizingpowermanagement for fuel cellhybridscootersofdifferentsizedcomponents. International JournalofHydrogenEnergy, 40(15), $5197-$ 5209.

Sarrazin, M., Fodorean, D., Gillijns, S., Peeters, B., Van DerAuweraer, H., \&Martis, C. (2014). Multiphysicalanalysisof a three-phase PWM-supplied PMSM for lightvehicleapplications. Proceedingsof ISMA 2014 - International ConferenceonNoiseandVibrationEngineeringand USD 2014 International ConferenceonUncertaintyinStructural Dynamics, pp. 1401-1414.

Walker,

P.

D., \&Roser,

$\mathrm{H}$.

M.

(2015).

Energyconsumptionandcostanalysisofhybridelectricpowertrainconfigurations

for twowheelers. AppliedEnergy, 146, 279-287.

Wang, Y., Ou, K., \&Kim, Y. (2015). Modelingand experimental validationofhybridprotonexchangemembrane fuel cell/batterysystem for powermanagement control. International JournalofHydrogenEnergy, 40(35), 11713-11721. 